\title{
EFFECT OF DAM LOCATION ON THE PERFORMANCE CHARACTERISTICS OF TWO -LOBE BEARING: MICROPOLAR LUBRICATED
}

\author{
Sanyam Sharma and Murali Krishna Chimata \\ Department of Mechanical Engineering \\ Maulana Azad National Institute of Technology, Bhopal
}

\begin{abstract}
This paper presents the effect of pressure dam parameters on the static and dynamic characteristics of two lobe pressure dam bearing. The modified Reynolds equation is derived on the basis of micropolar fluid theory. The Galerkin approach of finite element method has been used to solve modified Reynold's equation for carrying out the performance characteristics. The characteristics, which have been calculated for a wide range of dam parameters, have been found to be greatly influenced with the variation of the micropolar parameters. Effect of various dam locations is presented on two micropolar parameter, coupling number (N2) which couples the linear and angular momentum equation, arising the micro rotational effect of the suspended particles in the fluid and characteristics length (lm) which represents the interaction between the micropolar fluid and the film gap.
\end{abstract}

\section{KEYWORDS}

Micropolar lubrication, pressure dam, characteristics length, coupling number, dam location, finite element method.

\section{Nomenclature}

$\begin{array}{ll}\mathrm{C} & \text { radial clearance } \\ \mathrm{Cm} & \text { minor clearance } \\ \mathrm{R} & \text { radius of journal } \\ \mathrm{D} & \text { journal diameter } \\ \mathrm{O}_{\mathrm{u},} \mathrm{O}_{\mathrm{L}} & \text { upper lobe centre, lower centre } \\ \mathrm{O}_{\mathrm{j} .} \mathrm{O}_{\mathrm{B}} & \text { journal centre, bearing centre } \\ h & \text { film thickness } \\ \bar{h} & \text { non-dimensional film thickness } \\ p & \text { fluid film pressure } \\ \bar{p} & \text { non-dimensional film pressure } \\ \mathrm{U} & \text { velocity of journal } \\ \omega & \text { angular speed of journal } \\ \mathcal{E} & \text { eccentricity ratio } \\ \varepsilon_{1}, \varepsilon_{2} & \text { lobe eccentricity ratio, } \mathrm{e}_{1} / \mathrm{c}, \mathrm{e}_{2} / \mathrm{c} \\ D_{w}, L_{t} & \text { dam width, Relief track width } \\ \bar{D}_{w}, \bar{L}_{t} & D_{w} / \mathrm{L}, L_{t} / \mathrm{L} \\ D_{d} & \text { dam depth }\end{array}$

DOI : $10.14810 /$ ijmech.2015.4107 


$\begin{array}{ll}\bar{D}_{d} & D_{d} / \mathrm{c} \\ D A & \text { Dam angle in degree (location) } \\ \delta_{v} & \delta_{v}=\frac{d_{v}}{c} \\ \mathrm{~L} & \text { bearing axial length } \\ \phi & \text { attitude angle of the bearing } \\ \phi_{1}, \phi_{2} & \text { angles } \\ \mathrm{X}, \mathrm{Y}, \mathrm{Z} & \text { cartesian coordinate axis } \\ \bar{W}_{h}, \bar{W}_{v} & \text { non dimensional load components } \\ \mu & \text { viscocity of the newtonian fluid } \\ \mu_{\mathrm{v}} & \text { viscocity of the base fluid } \\ \mathrm{l}_{\mathrm{m}} & \text { non dimensional characteristics length } \\ \mathrm{N}^{2} & \text { coupling number }\end{array}$

\section{INTRODUCTION}

In contrast to plain cylindrical bearing, two lobe bearing is widely acceptable in high speed rotating machines. The use of two lobe bearings, considered to be more stable than ordinary plain cylindrical bearings, at lower speed. To satisfy the stability criteria of two lobe bearing, pressure dam is provided in bearing, due to their higher threshold speed of instability. To overcome instability at much higher speed, many changes have been incorporated in bearing design such as bearing geometry and pressure dams. The improvement in stability is the result of providing the step or dam cut in the upper surface of the bearing. From stability point of view, much work has been done on the pressure dam bearing using newtonion lubricant.

Some researchers [1-3] examined the stability for various circular and lobed pressure dam bearings. Step journal bearing by Nicholas et al. [1], elliptical bearing with pressure dam by Mehta et al. [2], four lobe bearing with pressure dam by Bhushan et al. [3]. All the results revealed that stability of lobed bearing increased by providing the pressure dam. Earlier the stability of a finite length step or pressure dam bearing is analyzed by [1]. Author investigated that stability can be improved by changing in the geometry of plain circular bearing. Stability of finite elliptical pressure dam bearings is determined by Mehta et al. [2], considering rotor flexibility effects. Authors evaluated stability of elliptical pressure dam bearings for various design parameters and pressure dam locations. They revealed that there is an improvement in stability of elliptical pressure dam bearings over cylindrical pressure dam bearing. Four lobe pressure dam bearing was investigated by Bhushan et al. [3] for the Dynamic characteristics; author found that dam location was the important parameter for stability investigation.

Some more researchers investigated the static and dynamic performance of circular and lobed bearing with micropolar lubricant. Researchers changed the fluid from newtonian to micropolar and investigated the performance for circular and lobed bearing and observed that enhancement in the performance can be achieved by changing the lubricant.Common works are, Das et al.[4], Nair et al. [5], Rahamatabadi et al. [6], Rahamatabadi et al. [7]. Sanyam and Rattan [8].The dynamic characteristics of hydrodynamic journal bearings lubricated with micropolar fluids were presented by Das and Guha [4] and they observed that higher threshold of stability is achieved in micropolar lubrication. Effect of volume concentration on damped frequency of whirl on elliptical journal bearing was presented by Nair et al. [5]; author found that the damped frequency of whirl decrease with increase in volume concentration of additives. Rahamatabadi [6] followed the [4] and investigated the static performance of lobed bearing with microploar lubrication and found that micropolar lubricants could produce significant increase in the static performance 
characteristics. Rahamatabadi et al. [7] evaluated the performance of circular and lobed bearing using generalized differential quadrature (GDQ) method and reported that the results were better as compared with FEM results. Hybrid journal bearing under non-newtonian fluid were examined by [9] and suggested that performance of bearing was greatly affected by operating condition and selection of parameters. [10] modified the fluid to micropolar fluid and examined the performance of multirecess hydrostatic journal bearing; flexibility effect of bearing shell is taken in to account. They found that performance is affected by flexibility of bearing shell. Performance of two lobe pressure dam bearing with micropolar lubricant were evaluated by Sharma and Rattan [8] and reported that two-lobe pressure dam bearing was superior to two-lobe bearing. Since micropolar fluid is found to have considerable effect on the performance characteristics of Twolobe pressure dam bearing. It is expected that the performance of two lobe pressure dam bearing system will also be affected by changing dam locations. The objective of this paper to investigate the combined effect of micropolarity parameter and dam parameter on two lobe pressure dam bearing.

\section{ANALYSIS}

\subsection{Bearing geometry}

A dam of depth $D_{d}$ and width $D_{w}$ is cut circumferentially to subtend an angle DA at bearing centre with split axis, in the direction of rotation. Figure 1 shows the schematic diagram of two lobe pressure dam bearing. The upper lobe is provided with pressure dam and lower lobe with relief track, as shown in Figure 2. Lengths $l_{1}$ and $l_{2}$ are circumferential lengths before and after dam. Performance analysis of such bearing is obtained by adding the individual lobe performance evaluated separately.

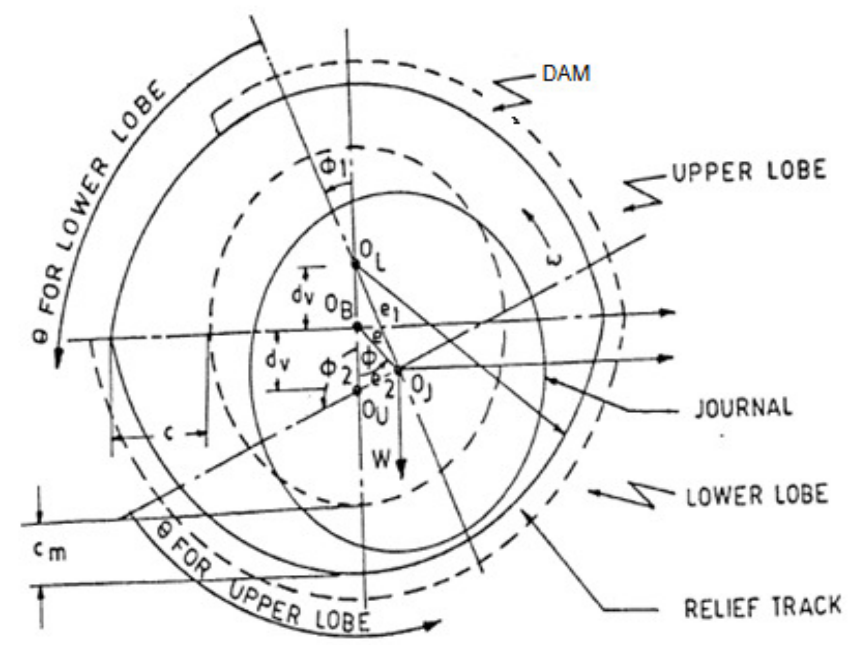

Figure 1. Two Lobe Pressure Dam Bearing [2] 


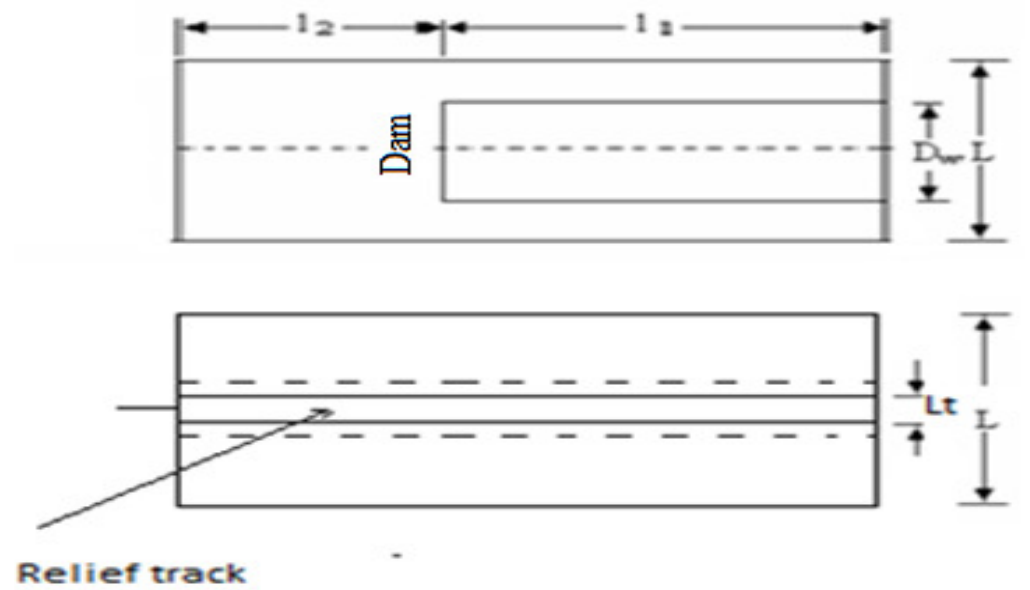

Figure 2. Pressure Dam geometry [2]

Lobe eccentricity ratios, angles for upper and lower lobe in degrees can be given by the following equations [2]

$$
\begin{aligned}
& \varepsilon_{1}{ }^{2}=\varepsilon^{2}+\delta_{v}{ }^{2}+2 \varepsilon \delta_{v} \cos \phi \\
& \varepsilon_{2}{ }^{2}=\varepsilon^{2}+\delta_{v}{ }^{2}-2 \varepsilon \delta_{v} \cos \phi \\
& \phi_{1}=\tan ^{-1}\left[\frac{\varepsilon \sin \phi}{\varepsilon \cos \phi+\delta_{v}}\right] 180 / \Pi \\
& \phi_{2}=\tan ^{-1}\left[\frac{\varepsilon \sin \phi}{\varepsilon \cos \phi-\delta_{v}}\right] 180 / \Pi
\end{aligned}
$$

\subsection{Modified Reynolds equation}

Based on the work of Das et al. [4] the modified Reynolds equation under usual assumption as follows:

$\frac{\partial}{\partial x}\left[\frac{h^{3}}{\mu} \phi(\Lambda, N, h) \frac{\partial p}{\partial x}\right]+\frac{\partial}{\partial z}\left[\frac{h^{3}}{\mu} \phi(\Lambda, N, h) \frac{\partial p}{\partial z}\right]=6 \mathrm{U} \frac{\partial h}{\partial x}+12 \frac{\partial h}{\partial t}$

Where,

$$
\begin{aligned}
& \phi(\Lambda, N, h)=1+12 \frac{\Lambda^{2}}{h^{2}}-6 \frac{N \Lambda}{h} \operatorname{coth}\left(\frac{N h}{2 \Lambda}\right) \\
& N=\left(\frac{\chi}{2 \mu+\chi}\right)^{1 / 2}, \Lambda=\left(\frac{\gamma}{4 \mu}\right)^{1 / 2}, \mu_{v}=\mu+\frac{1}{2} \gamma
\end{aligned}
$$

The parameter $\mu_{v}$ and $\mu$ represent the viscosity of the base fluid and the viscosity of the Newtonian fluid, respectively. $\chi$ and $\gamma$ are the spin viscosity and the material coefficient, respectively for the micropolar fluid, $\mathrm{h}$ is the film thickness and $\mathrm{P}$ is the micropolar film pressure in the bearing. $N^{2}$ and $\Lambda$ are the two important parameters of a micropolar fluid. Linear and 
angular momentum equations are coupled by a parameter $N^{2}$, called the coupling, number, another parameter $\Lambda$ is called characteristics length of the micropolar fluid. As $\Lambda$ becomes zero Equation (3) reduces for newtonian fluid. Following dimensionless quantities are used:

$$
\operatorname{lm}=\frac{c}{\Lambda}, \theta=\frac{x}{R}, \bar{h}=\frac{h}{c_{m}}, \bar{z}=\frac{z}{L}, \bar{p}=\frac{p c_{m}{ }^{2}}{\mu U R}
$$

The generalized form of the reynolds equation for micropolar fluids, given below [6]:

$$
\frac{\partial}{\partial \theta}\left[\frac{\Psi(\Lambda, N, \bar{h})}{\mu} \frac{\partial \bar{p}}{\partial \theta}\right]+\left(\frac{R}{L}\right)^{2} \cdot \frac{\partial}{\partial \bar{z}}\left[\frac{\Psi(\Lambda, N, \bar{h})}{\mu} \frac{\partial \bar{p}}{\partial \bar{z}}\right]=6 \frac{\partial \bar{h}}{\partial \theta}+12 \frac{\partial \bar{h}}{\partial t}
$$

Where,

$$
\phi(\Lambda, N, \bar{h})=\bar{h}^{3}+12 \frac{\bar{h}}{l_{m}{ }^{2}}-6 \frac{N \bar{h}^{2}}{l_{m}} \operatorname{coth}\left(\frac{N \bar{h} l_{m}}{2}\right)
$$

\subsection{Solution procedure}

Equation (5) is solved by finite element method, using Galerkin's approach. The domain is divided in to four noded isoparametric elements, such as 100 elements in circumferential direction and 120 elements in the axial direction. The elements matrices are generated for all elements and assembled to get global coefficient matrix. Thus Finite element equations are obtained. Fluid film pressures are computed at nodal points by applying Reynolds' boundary conditions as given in Eq. (6)-(8).

Pressure boundary conditions are applied

$$
\begin{aligned}
& \bar{P}(\theta, \bar{Z})=0 \text { at } \theta=0, \theta_{2} \\
& \bar{P}(\theta, \bar{Z})=0 \text { at } \bar{z}= \pm 1 \\
& \frac{\partial \bar{p}}{\partial \theta}(\theta, z)=0 \text { at } \theta=\theta_{2}
\end{aligned}
$$

\section{Performance Characteristics}

The static and dynamic characteristics such as load carrying capacity, attitude angle, stiffness coefficients, damping coefficients, damped frequency of whirl and journal critical mass are determined for various micropolar parameters $\left(N^{2}\right.$ and $\left.l m\right)$ and Dam parameters.

\subsection{Fluid film stiffness coefficients}

Fluid film stiffness coefficients are calculated using following equations [11]:

$$
\bar{K}_{i j}=\frac{\partial \bar{W}_{i}}{\partial \bar{s}_{j}}, \quad(\mathrm{i}=\mathrm{x}, \mathrm{y})
$$

Where, $i$ represents the direction of force. 
$\bar{s}_{j}=$ Direction of journal center displacement $\left(\bar{s}_{j}=\bar{x}_{j}, \bar{y}_{j}\right)$

\subsection{Fluid film damping coefficients}

$\bar{C}_{i j}=\frac{\partial \bar{W}_{i}}{\partial \overline{\dot{s}}_{j}}, \quad(\mathrm{i}=\mathrm{x}, \mathrm{y})$,

Where $\overline{\dot{s}}_{j}$ is the velocity component of the journal center $\left(\overline{\dot{s}}_{j}=\bar{x}_{j}, \bar{y}_{j}\right)$

\subsection{Stability parameters}

When the natural frequency of journal system reaches the damped frequency of whirl, instability arises. The damped frequency of whirl $\omega_{d}$ is given below [5]. By using the stiffness coefficients and damping coefficients, stability parameters such as damped frequency of whirl and critical mass are obtained.

$$
\omega_{d}{ }^{2}=\frac{\left(K_{x x}-\lambda\right)\left(K_{y y}-\lambda\right)-K_{x y} K_{y x}}{C_{x x} C_{y y}-C_{x y} C_{y x}}
$$

Where

$$
\lambda=\frac{K_{x x} C_{y y}+K_{y y} C_{x x}-K_{x y} C_{y x}-K_{y x} C_{x y}}{C_{x x}+C_{y y}}
$$

A negative value of $\omega_{d}$ means, no whirl is there.

The ratio of $\lambda$ and $w_{d}{ }^{2}$ is called critical mass $\left(M_{c}\right)$

$$
M_{c}=\frac{\lambda}{\omega_{d}^{2}}
$$

\section{RESULTS AND DISCUSSION}

Performance of such bearing is investigated on the basis of micropolarity parameters and pressure dam parameters. For the analysis purpose, the static and dynamic characteristics of such bearing various results are plotted. The following values are chosen for the study of static and dynamic characteristics of such bearing.

$$
\bar{D}_{w}=0.40, \bar{D}_{d}=0.25, \bar{L}_{t}=0.25, \xi=0.3, \frac{L}{D}=1.6
$$

The results clearly represent the effect of the dam locations (dam angles) in degrees (DA) on the performance characteristics of two lobe pressure dam bearing. 
International Journal of Recent advances in Mechanical Engineering (IJMECH) Vol.4, No.1, February 2015

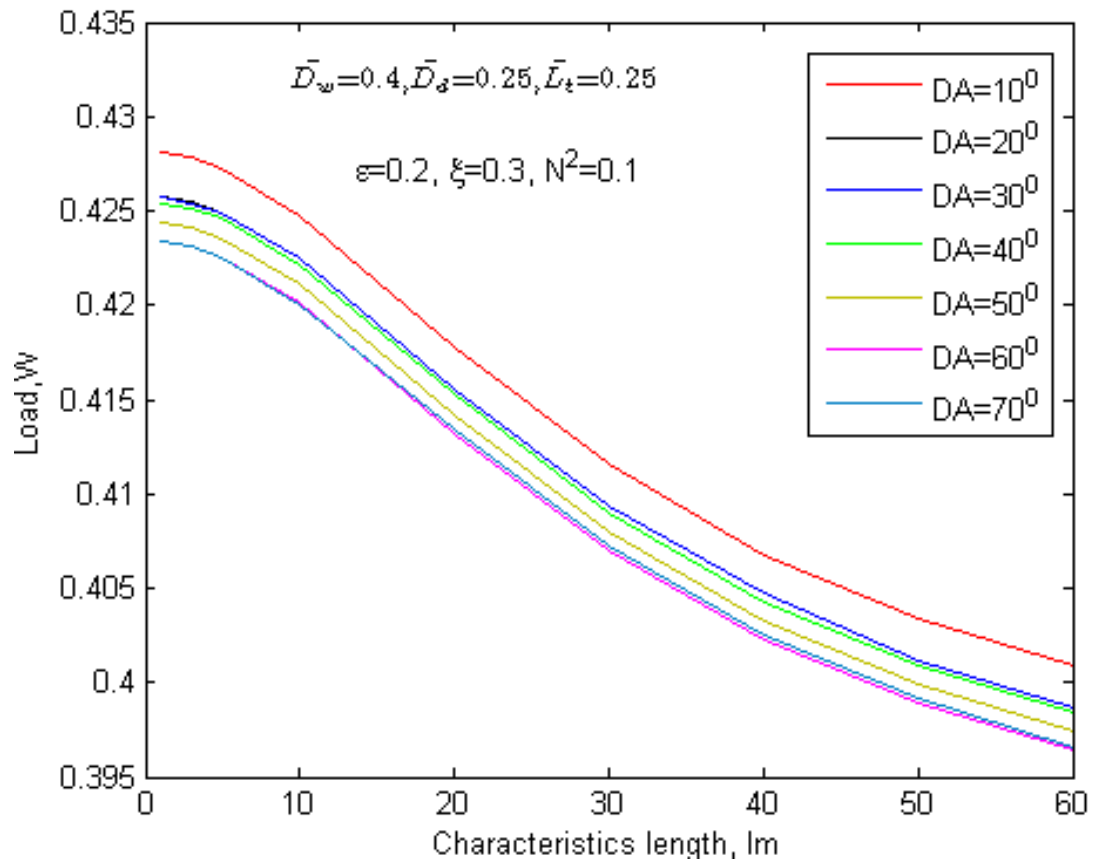

Figure 3. Variation of load carrying capacity as a function of ' $1 \mathrm{~m}$ ' for various values of 'DA' and $\mathrm{N}^{2}=0.1$

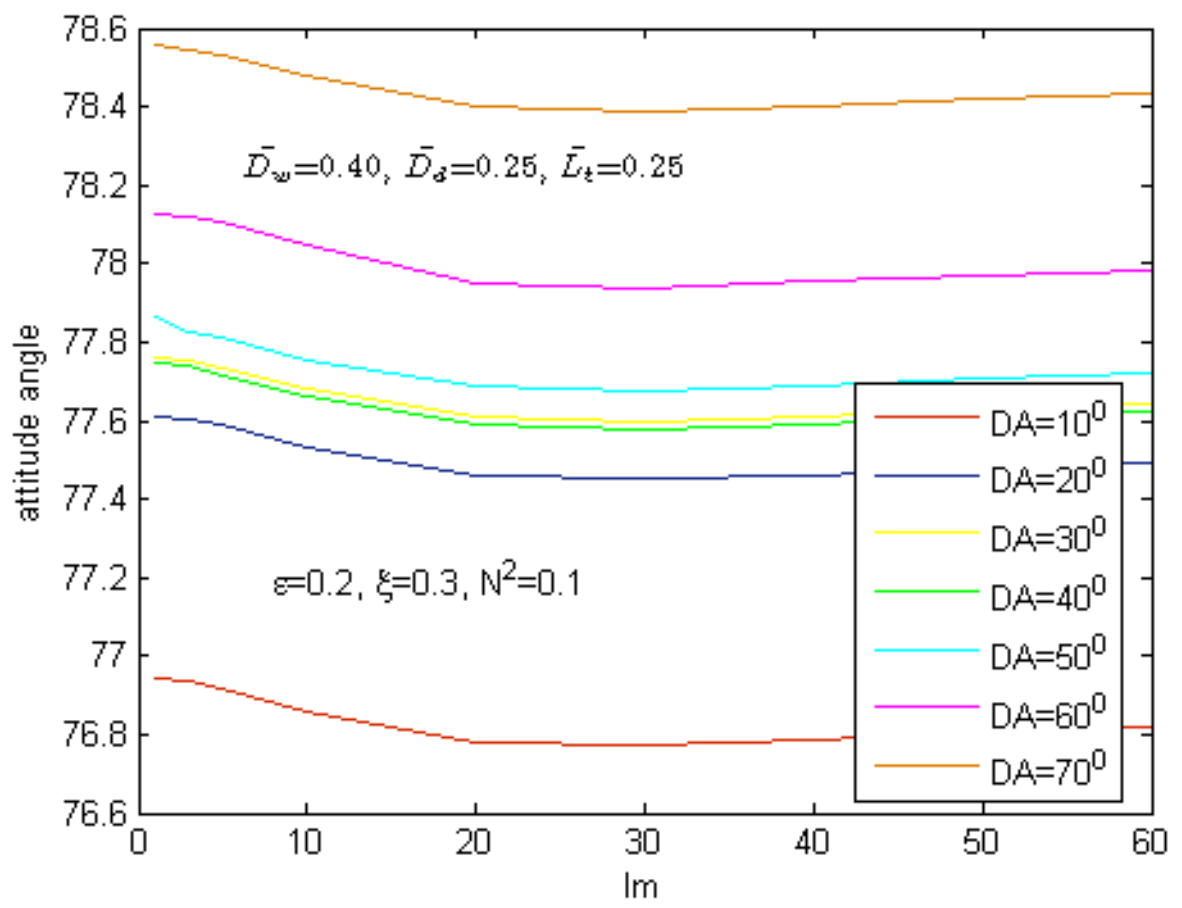

Figure 4. Variation of attitude angle $(\phi)$ as a function of ' $1 \mathrm{~m}$ ' for various values of 'DA' and $\mathrm{N}^{2}=0.1$ 


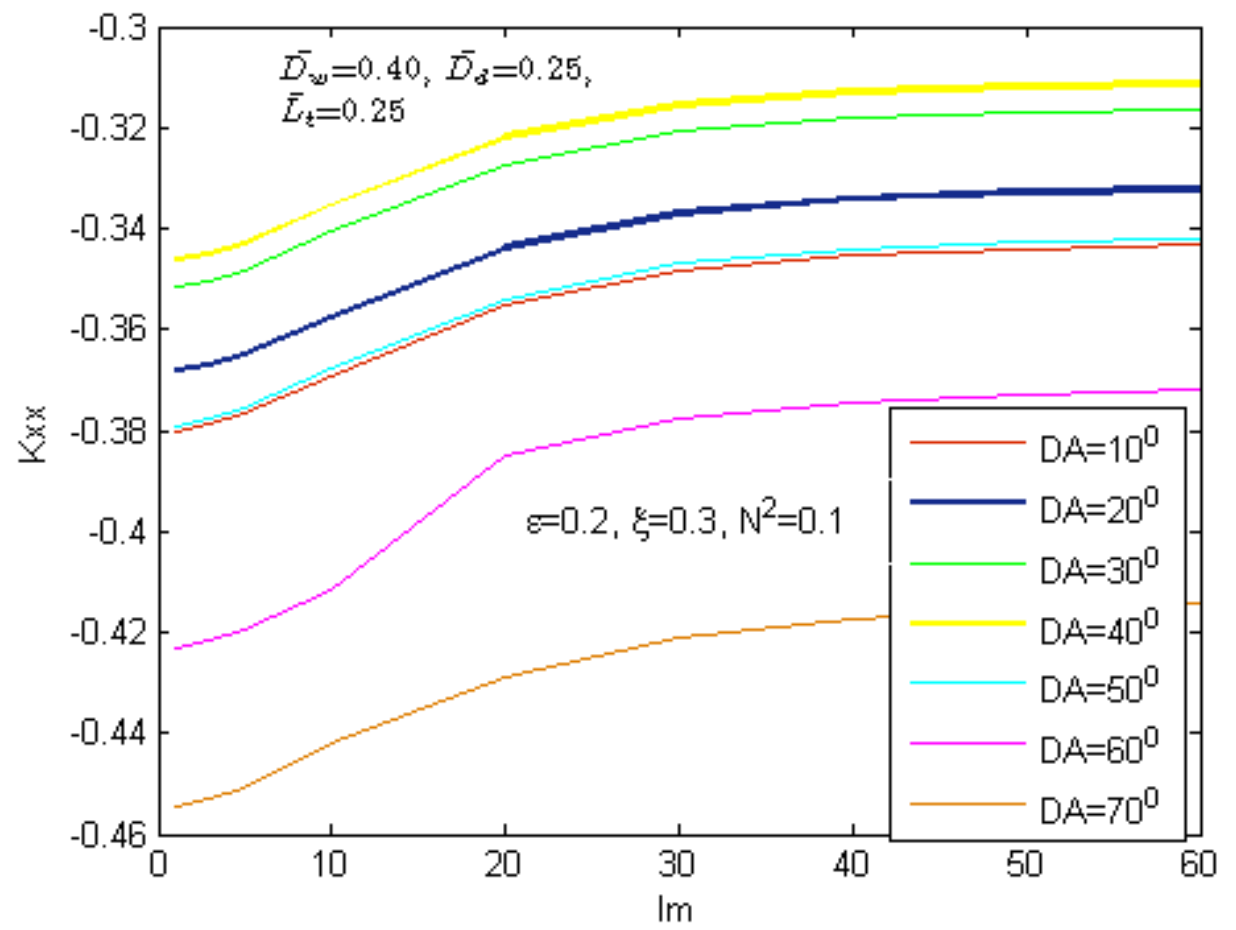

Figure 5. Variation of stiffness coefficient $\left(\mathrm{K}_{\mathrm{xx}}\right)$ as a function of ' $1 \mathrm{~m}$ ' for various values of 'DA' and $\mathrm{N}^{2}=0.1$

Fig. 3 depicts that Load carrying capacity is maximum at dam location of $10^{0}$, while found minimum at $60^{\circ}$. Load carrying capacity is found in decreasing trend with increase in characteristics length $\mathrm{lm}$. Fig. 4 depicts that attitude angle is maximum at dam location of $70^{\circ}$ and minimum at $10^{\circ}$. It is also observed that for a particular value of dam location, attitude angle is higher at lower value of characteristics length $(\mathrm{lm})$ and then decreases up to a particular $1 \mathrm{~m}=20$, then remains constants, for all values of characteristics length. Fig. 5 depicts that stiffness $K_{x x}$ found maximum at dam location of $40^{\circ}$ and reported minimum at $70^{\circ}$. It is also observed of increasing trend with increase in characteristics length $1 \mathrm{~m}$.

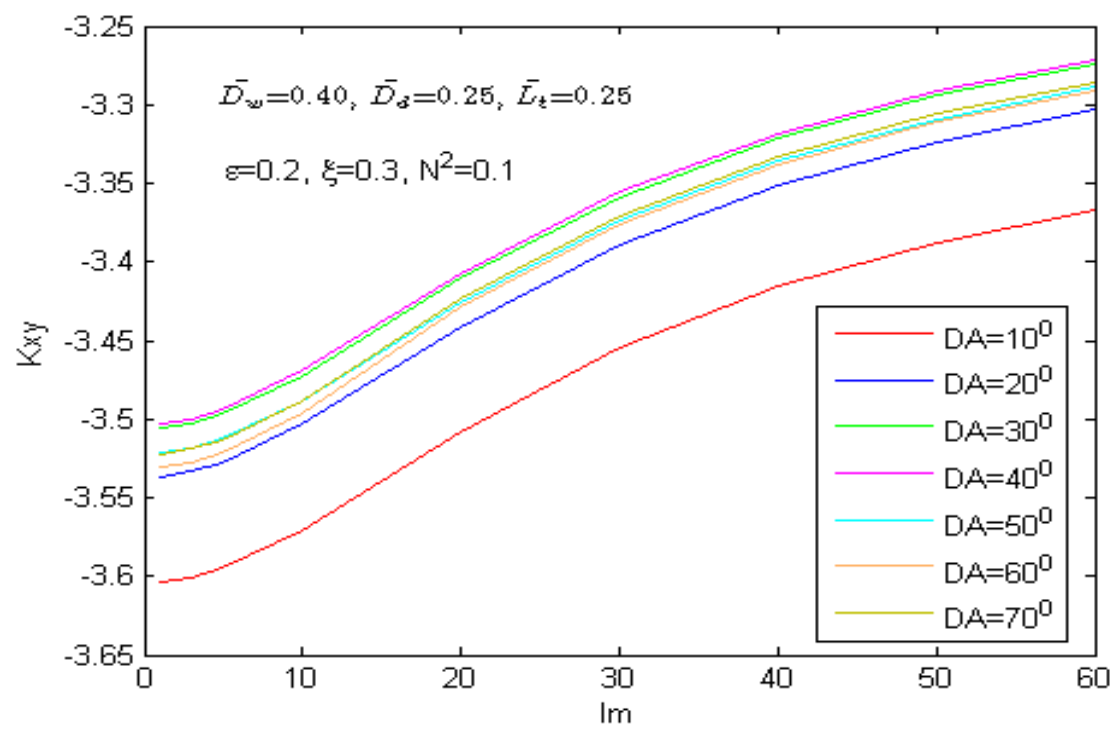

Figure 6. Variation of stiffness coefficient $\left(\mathrm{K}_{\mathrm{xy}}\right)$ as a function of ' $1 \mathrm{~m}$ ' for various values of 'DA' and $\mathrm{N}^{2}=0.1$ 
International Journal of Recent advances in Mechanical Engineering (IJMECH) Vol.4, No.1, February 2015

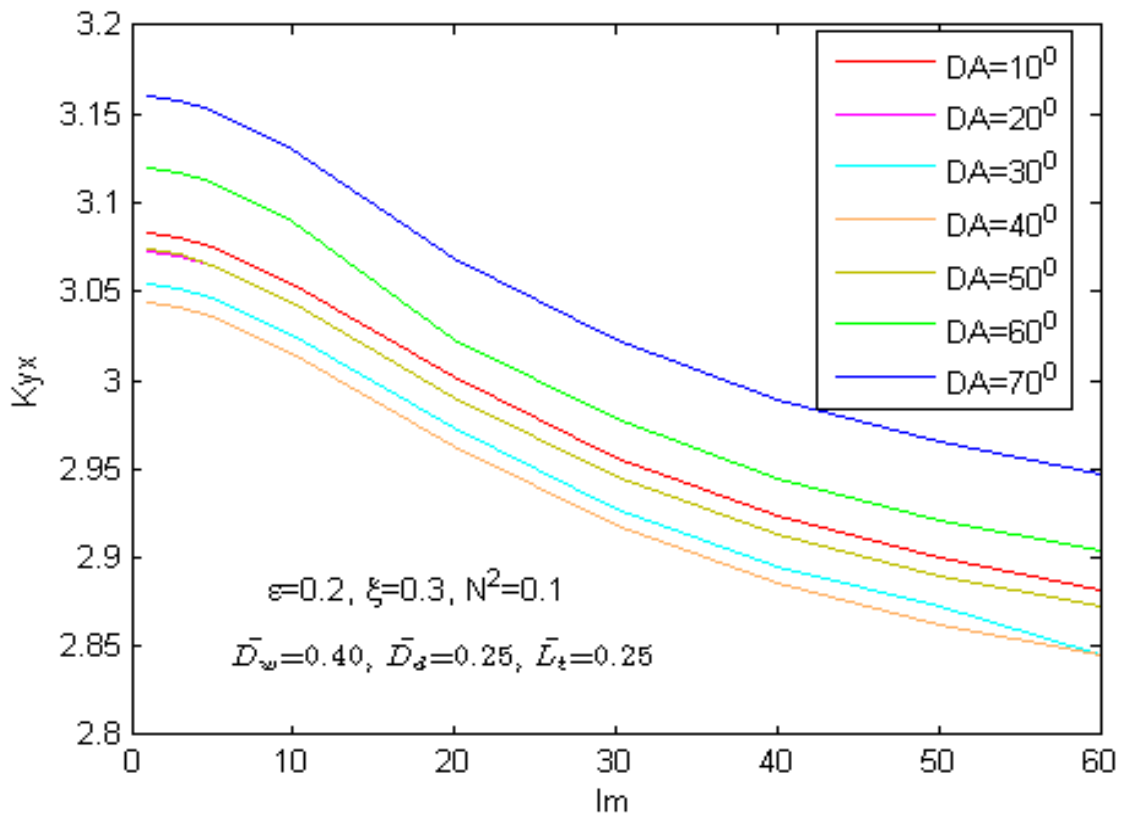

Figure 7. Variation of stiffness coefficient $\left(\mathrm{K}_{\mathrm{yx}}\right)$ as a function of ' $1 \mathrm{~m}$ ' for various values of 'DA' and $\mathrm{N}^{2}=0.1$

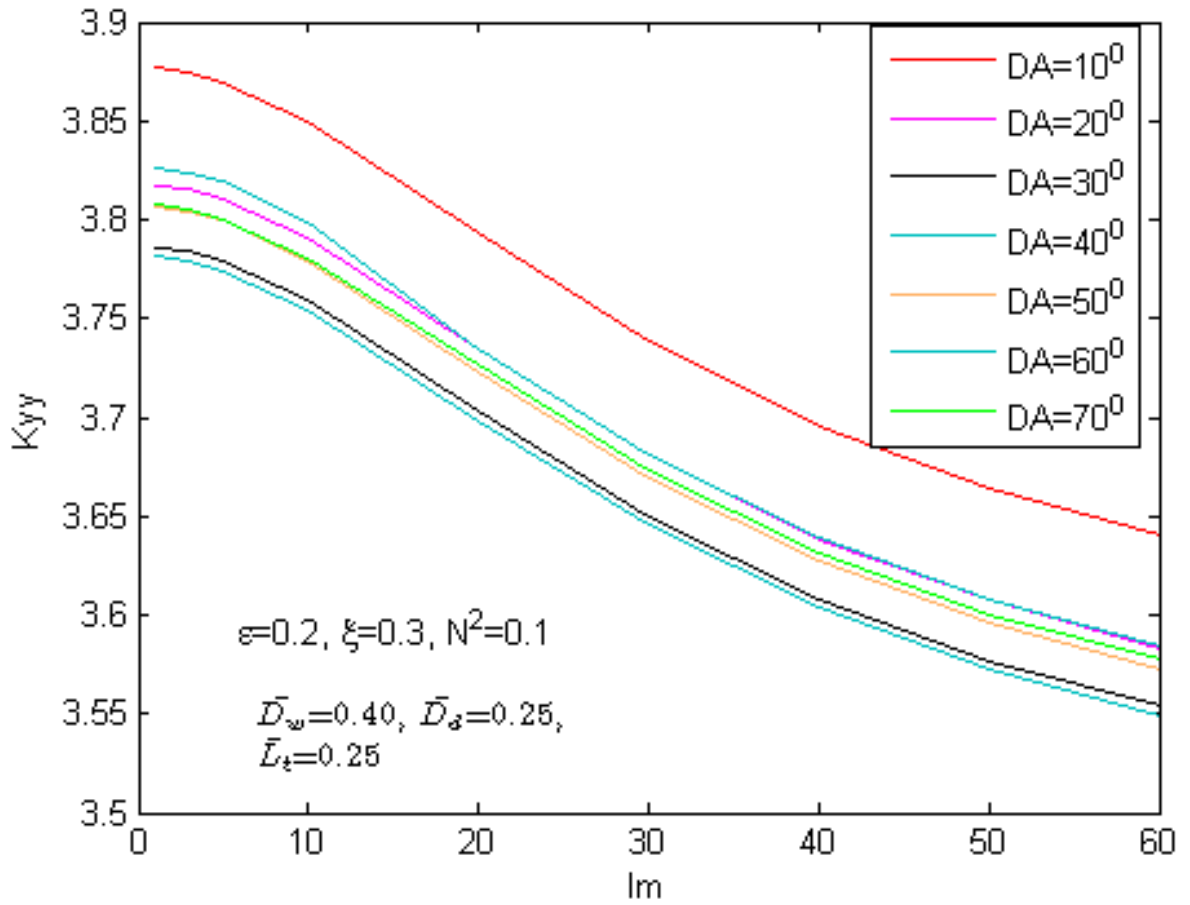

Figure 8. Variation of stiffness coefficient $\left(\mathrm{K}_{\mathrm{yy}}\right)$ as a function of ' $1 \mathrm{~m}$ ' for various values of 'DA' and $\mathrm{N}^{2}=0.1$ 


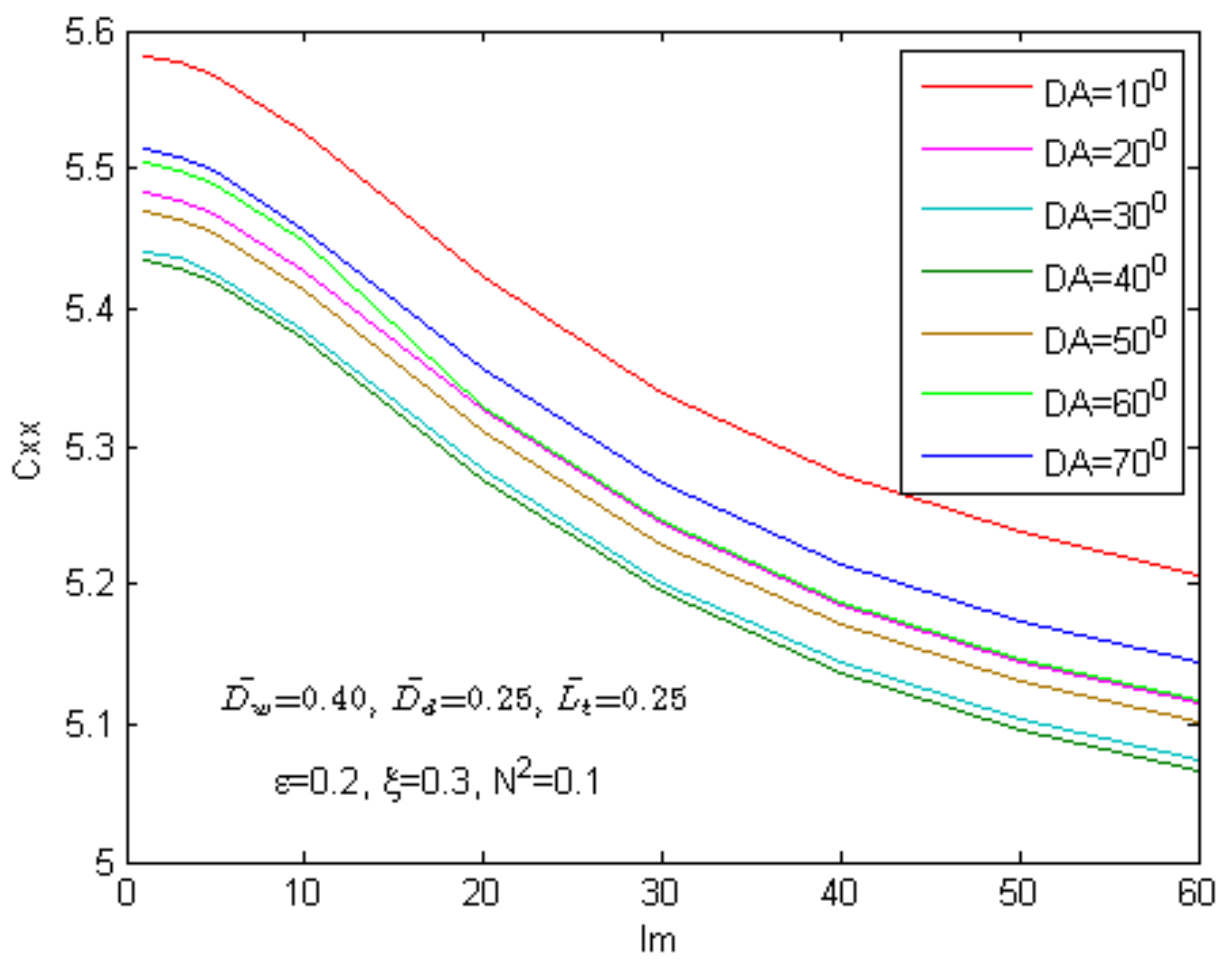

Figure 9. Variation of damping coefficient $\left(\mathrm{C}_{\mathrm{xx}}\right)$ as a function of ' $\mathrm{lm}$ ' for various values of 'DA' and $\mathrm{N}^{2}=0.1$

Fig. 6 depicts that stiffness coefficient $\mathrm{K}_{\mathrm{xy}}$ seems to be maximum at dam location of $40^{\circ}$ and reported minimum at $10^{\circ}$. It is also observed that for a particular dam location, $\mathrm{K}_{\mathrm{xx}}$ and $\mathrm{K}_{\mathrm{xy}}$ is higher at lower value of characteristics length $(1 \mathrm{~m})$ and decreases as $1 \mathrm{~m}$ increases. Behavior of $\mathrm{K}_{\mathrm{yx}}$ and $\mathrm{K}_{\mathrm{yy}}$ are found on same pattern as shown in Fig. 7 and Fig. 8, while Fig. 9 depicts that stiffness coefficient $\mathrm{C}_{\mathrm{xx}}$ is maximum at dam location of $10^{\circ}$ and reported minimum at $40^{\circ}$. It is also observed that for a particular dam location, $\mathrm{C}_{\mathrm{xx}}$ is higher at lower value of characteristics length (lm) and decreases as $\operatorname{lm}$ increases.

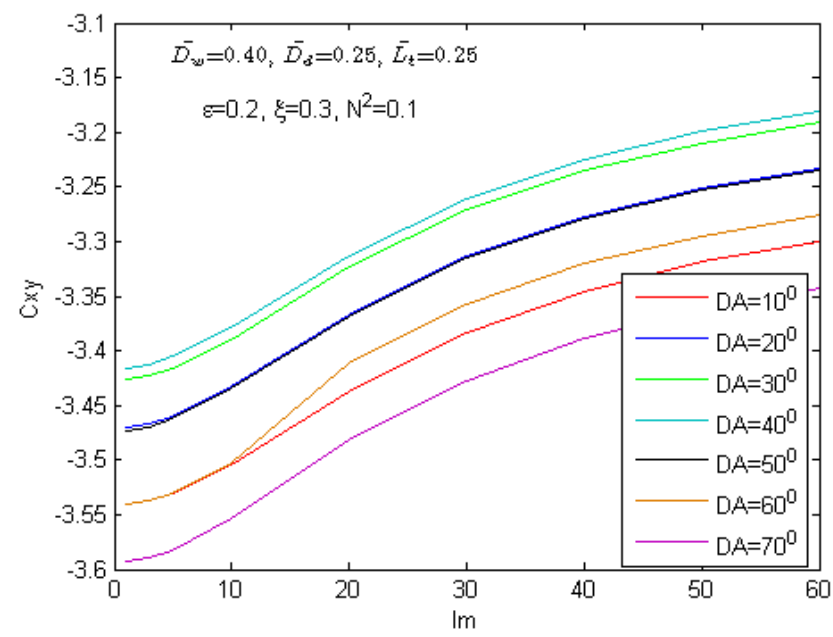

Figure 10. Variation of damping coefficient $\left(\mathrm{C}_{\mathrm{xy}}\right)$ as a function of ' $\mathrm{lm}$ ' for various values of 'DA' and $\mathrm{N}^{2}=0.1$ 
International Journal of Recent advances in Mechanical Engineering (IJMECH) Vol.4, No.1, February 2015

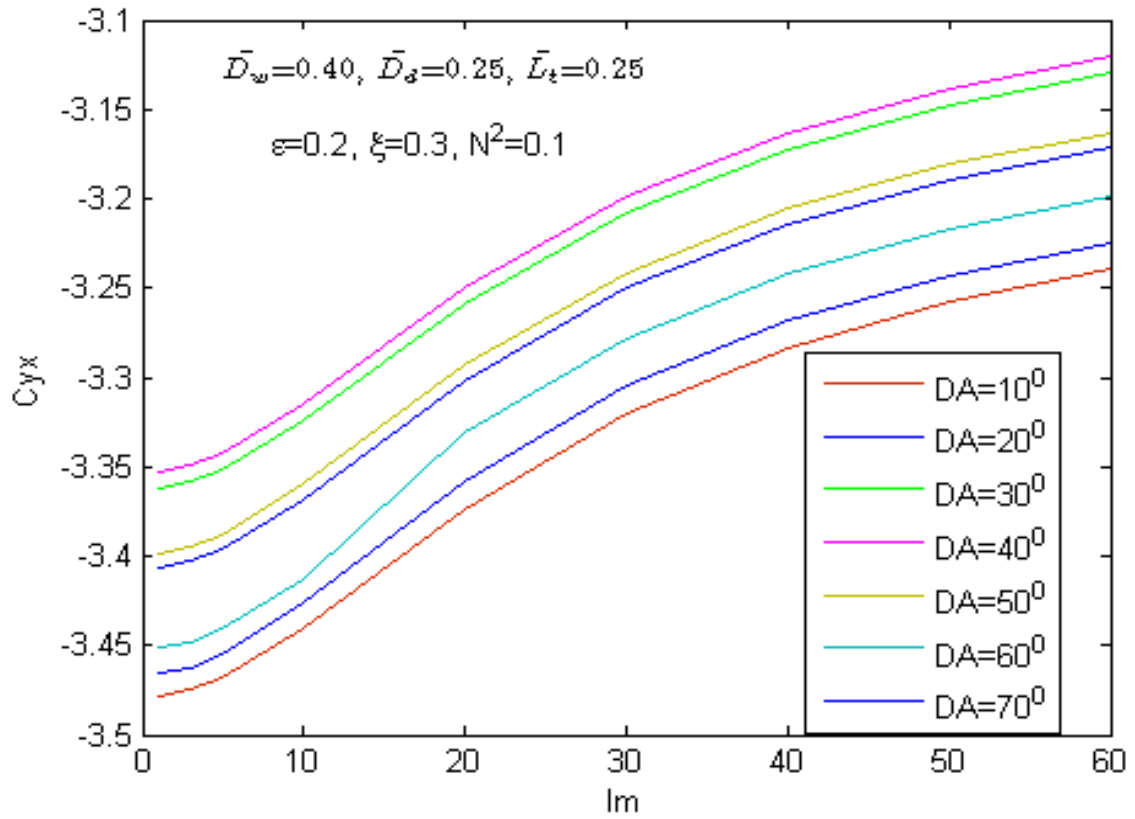

Figure 11.Variation of damping coefficient $\left(\mathrm{C}_{\mathrm{yx}}\right)$ as a function of ' $\mathrm{lm}$ ' for various values of 'DA' and $\mathrm{N}^{2}=0.1$

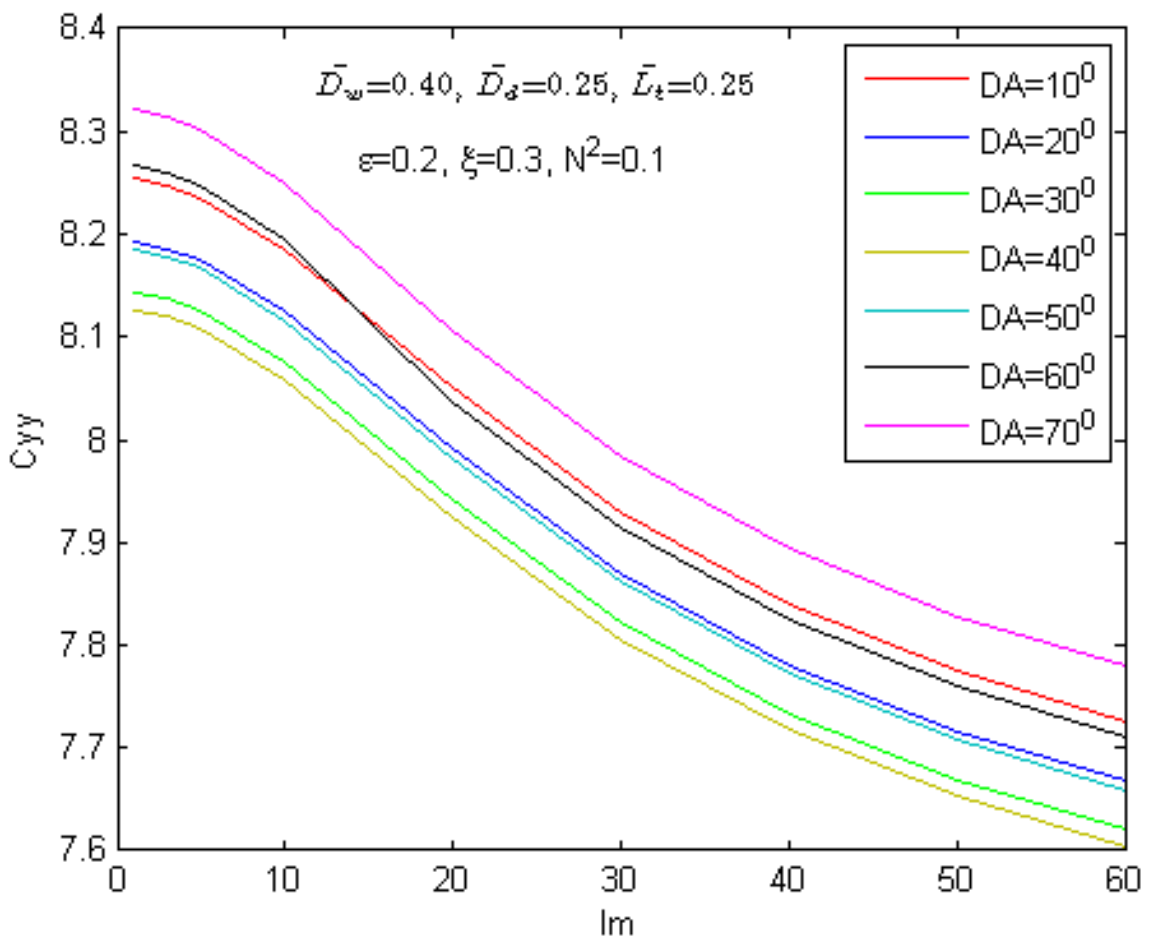

Figure 12 Variation of damping coefficient $\left(\mathrm{C}_{\mathrm{yy}}\right)$ as a function of ' $\mathrm{lm}$ ' for various values of 'DA' and $\mathrm{N}^{2}=0.1$

Fig. 10 depicts that stiffness coefficient $\mathrm{C}_{\mathrm{xy}}$ is maximum at dam location of $70^{\circ}$ and reported minimum at $40^{\circ}$. It is also observed that for a particular dam location, $\mathrm{C}_{\mathrm{xy}}$ is higher at lower value of characteristics length $(\mathrm{lm})$ and increases as $1 \mathrm{~m}$ increases. Fig. 11 shows that $\mathrm{C}_{\mathrm{yx}}$ is found 
International Journal of Recent advances in Mechanical Engineering (IJMECH) Vol.4, No.1, February 2015

maximum at $40^{\circ}$ and minimum at $10^{\circ}$, of increasing trend. Fig. 12 shows $\mathrm{C}_{\mathrm{yy}}$ is found maximum at $70^{\circ}$ and minimum at $40^{\circ}$.

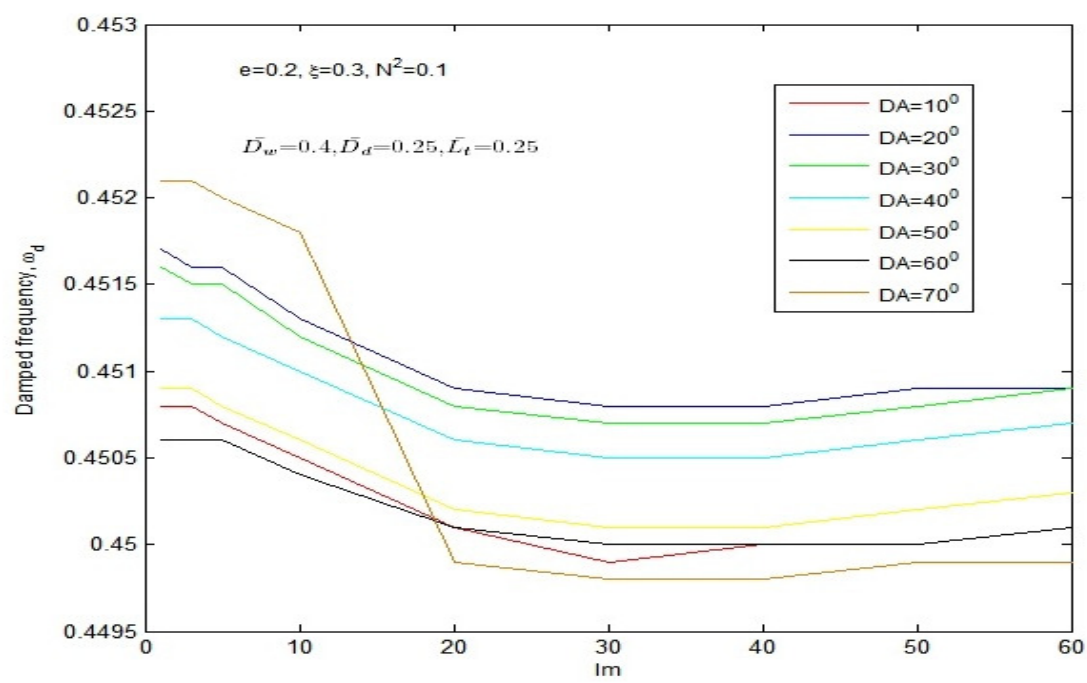

Figure 13. Variation of damped frequency of whirl $\left(\omega_{d}\right)$ as a function of 'Im' for various values of 'DA',

$$
\mathrm{N}^{2}=0.1
$$

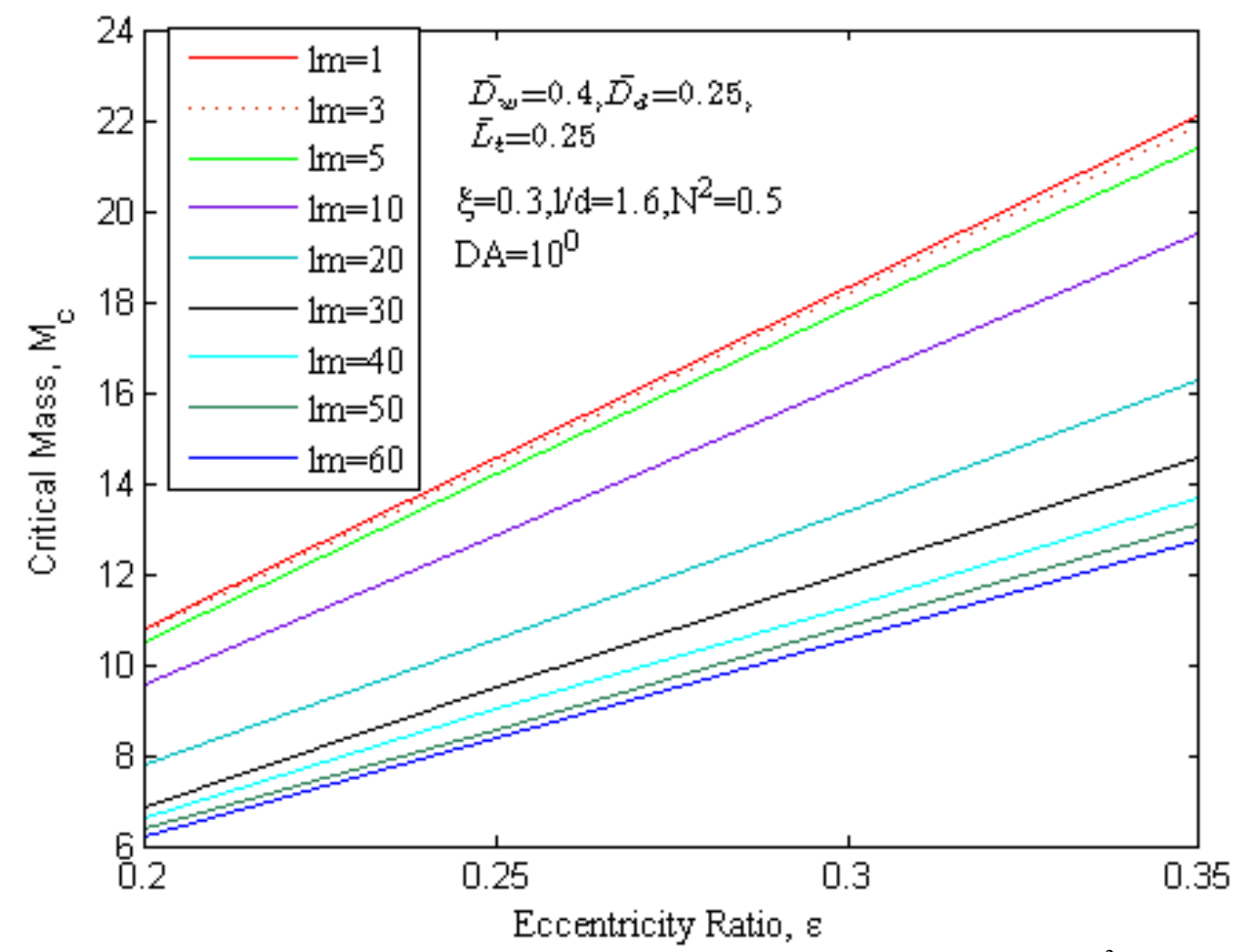

Figure 14. Variation of critical mass 'Mc' as a function of ' $E$ ' for various values of ' $1 \mathrm{~m}$ ', $\mathrm{N}^{2}=0.5, \mathrm{DA}=10^{0}$ 


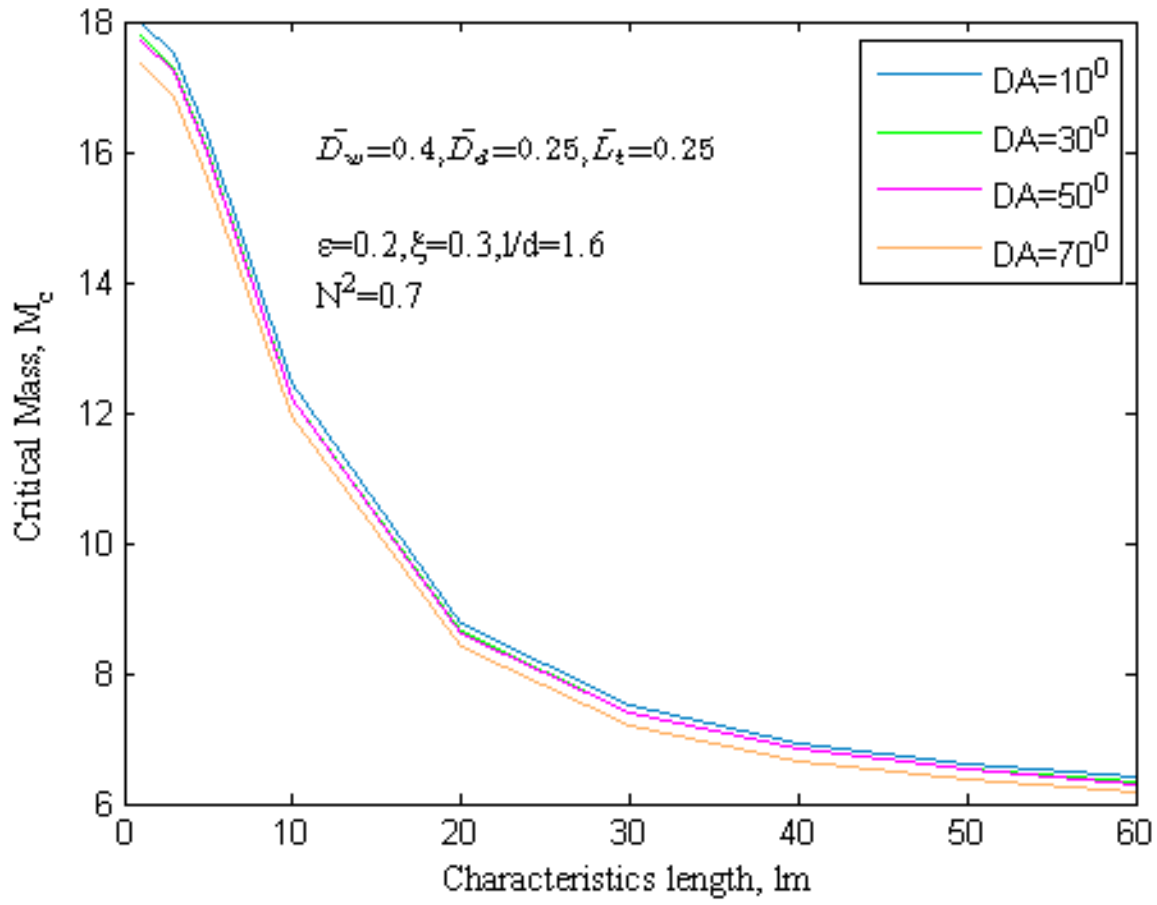

Figure 15. Variation of critical mass ' $\mathrm{Mc}$ ' as a function of ' $1 \mathrm{~m}$ ' for various values of 'DA', $\mathrm{N}^{2}=0.7, \varepsilon=0.2$

The combined effect micropolar parameter and dam location parameter on damped frequency of whirl of two lobe pressure dam bearing is studied in Fig. 13, as a parametric variation of DA. The coupling number $\mathrm{N}^{2}=0.1, \mathcal{E}=0.2$ are held constant for analysis, to observe the effect of characteristics length $(\mathrm{lm})$ as a micropolar parameter. It shows that the damped frequency of whirl increases with increase in DA, irrespective of $1 \mathrm{~m}$. The damped frequency at $\mathrm{DA}=70^{\circ}$ is higher up to $\mathrm{lm}=10$, then suddenly drop and found to be minimum, while comparing with other dam angles. It increases gradually with increases in ' $1 \mathrm{~m}$ '. For other dam angles (except $70^{\circ}$ ), damped frequency decreases initially and then increases after a particular 'Im'. It also supports that there exist an optimal value of $1 \mathrm{~m}$ for which damped frequency of whirl, for each dam angle (DA) is minimum. Fig.14 depicts the critical mass variation with eccentricity, for various values of 'Im'. It is observed that critical mass ' $\mathrm{Mc}$ ' increases with eccentricity ratio and found to be higher at lower material length i.e. $1 \mathrm{~m}=1$. Effect of dam angle location on critical mass is presented in Fig. 15. It is found that critical mass decreases with increase in characteristics length ' $1 \mathrm{~m}$ ' and observed higher value at smaller dam angle i.e. $\mathrm{DA}=10^{\circ}$.

\section{CONCluSions}

The following important conclusion can be drawn from the results discussed:

- The Load carrying capacity increases by introducing pressure dam in two-lobe bearing using micropolar lubrication.

- The attitude angles decreases when pressure dams and relief tracks are incorporated in ordinary two-lobe bearing with micropolar lubrication.

- Damped frequency of whirl also depends on eccentricity and dam angles. Lower frequency is achieved at smaller dam angle. 
- Journal critical mass depends on characteristics length and dam angle. For higher critical mass, low value of characteristics length and smaller dam location should be chosen.

\section{REFERENCES}

[1] J.C. Nicholas \&, P.E. Allaire (1980) "Analysis of step journal bearings- finite length stability", ASLE Transactions, Vol. 23, No. 2, pp197-207.

[2] N.P. Mehta, A. Singh \& B.K. Gupta (1986) "Stability of finite elliptical pressure dam bearings with rotor flexibility effects”, ASLE Transactions, Vol. 29, No. 4, pp548-557.

[3] G. Bhushan, S.S. Rattan \& N.P. Mehta (2002) "Stability analysis of four-lobe pressure dam bearings", Tribology Letters, Vol. 13, No. 13, pp1-7.

[4] S. Das, S. K. Guha \& A.K. Chattopadhyay (2005) "Linear stability analysis of hydrodynamic journal bearings under micropolar lubrication”, Tribology International, Vol. 38, No. 5, pp500-507.

[5] K.P. Nair, V.P.S.Nair \& N.H. Jayadas (2007) "Static and dynamic analysis of elastohydrodynamic elliptical journal bearing with micropolar lubricant”, Tribology International, Vol. 40, No. 1, pp297305.

[6] A.D. Rahamatabadi \& R. Rashidi (2009) "Micropolar lubricant effects on the performance of noncircular lobed bearing", Tribology International, Vol. 43, No. 1, pp.404-413. [7]A.D. Rahamatabadi, M.Z. Mehrjardi \& M.R. Fazel (2011) "Performance analysis of micropolar lubricated journal bearings using GDQ method”, Tribology International, Vol. 43, No. 11, pp.2000-2009.

[8] S. Sanyam \& S.S. Rattan (2010) "Micropolar lubricant effects on the performance of a two- lobe bearing with pressure dam”, Int. Journal of Engg. Sc. \& Tech. Vol. 2, No. 10, pp.5637-5646.

[9] R.K. Duvedi, H.C. Garg \& V.K. Jadon (2006) "Analysis of hybrid journal bearing for non-Newtonian lubricants”, Lubrication Science, Vol. 18, No. 3, pp.187-207.

[10] S. Verma, V. Kumar \& K.D. Gupta (2012) "Performance analysis of flexible multirecess hydrostatic journal bearing operating with micropolar lubricant", Lubrication Science, Vol. 24, No. 6, pp.273292.

[11] R. Dhawan \& S. Verma (2013) "Analyzing Micropolar Lubrication in Noncircular Hybrid Journal Bearings”, Tribology Transactions, Vol. 57, No. 2, pp.182-189.

[12] N.P. Mehta, S.S. Rattan \& R. Verma (2010) "Stability analysis of two-lobe hydrodynamic journal bearing with couple stress lubricant", ARPN Journal of Engineering and Applied Sciences, Vol. 5. No. 1, pp. 69-74. 